\title{
Toward an integrated approach to crop production and pollination ecology through the application of remote sensing
}

\author{
Bryony K Willcox ${ }^{\text {Corresp., }}{ }^{1}$, Andrew J Robson ${ }^{2}$, Brad G Howlett ${ }^{3}$, Romina Rader ${ }^{1}$ \\ ${ }^{1}$ School of Environmental and Rural Science, University of New England, Armidale, NSW, Australia \\ 2 Precision Agriculture Research Group, University of New England, Armidale, NSW, Australia \\ 3 The New Zealand Insitute for Plant and Food Research, Christchurch, New Zealand \\ Corresponding Author: Bryony K Willcox \\ Email address: bk_willcox@hotmail.com
}

Insect pollinators provide an essential ecosystem service by transferring pollen to crops and native vegetation. The extent to which pollinator communities vary both spatially and temporally has important implications for ecology, conservation and agricultural production. However, understanding the complex interactions that determine pollination service provisioning and production measures over space and time has remained a major challenge. Remote sensing technologies (RST), including satellite, airborne and ground based sensors, are effective tools for measuring the spatial and temporal variability of vegetation health, diversity and productivity within natural and modified systems. Yet, while there are synergies between remote sensing science, pollination ecology and agricultural production, research communities have only recently begun to actively connect these research areas. Here, we review the utility of RST in advancing crop pollination research and highlight knowledge gaps and future research priorities. We found that RST are currently used across many different research fields to assess changes in plant health and production (agricultural production) and to monitor and evaluate changes in biodiversity across multiple landscape types (ecology and conservation). In crop pollination research, the use of RST are limited and largely restricted to quantifying remnant habitat use by pollinators by ascertaining the proportion of, and/ or isolation from, a given land use type or local variable. Synchronization between research fields is essential to better understand the spatial and temporal variability in pollinator dependent crop production. RST enable these applications to be scaled across much larger areas than is possible with field-based methods and will facilitate large scale ecological changes to be detected and monitored. We advocate greater use of RST to better understand interactions between pollination, plant health and yield spatial variation in pollinator dependent crops. This more holistic approach is necessary for decision-makers to improve strategies toward managing multiple land use types and ecosystem services. 
1 Toward an integrated approach to crop production and pollination

2 ecology through the application of remote sensing

3

4 Bryony K Willcox ${ }^{1 *}$, Andrew J Robson ${ }^{2}$, Brad G Howlett ${ }^{3}$ and Romina Rader ${ }^{1}$

5

61 School of Environmental and Rural Science, University of New England, Armidale, NSW, Australia

72 Precision Agriculture Research Group, University of New England, Armidale, NSW, Australia

83 The New Zealand Institute for Plant and Food Research Limited, Private Bag 4704, Christchurch Mail

9 Centre, Christchurch 8140, New Zealand

10 *Corresponding author email: bk_willcox@hotmail.com

11 


\section{Abstract}

13 Insect pollinators provide an essential ecosystem service by transferring pollen to crops and native vegetation. The extent to which pollinator communities vary both spatially and temporally has important implications for ecology, conservation and agricultural production. However, understanding the complex interactions that determine pollination service provisioning and production measures over space and time has remained a major challenge. Remote sensing technologies (RST), including satellite, airborne and ground based sensors, are effective tools for measuring the spatial and temporal variability of vegetation health, diversity and productivity within natural and modified systems. Yet, while there are synergies between remote sensing science, pollination ecology and agricultural production, research communities have only recently begun to actively connect these research areas. Here, we review the utility of RST in advancing crop pollination research and highlight knowledge gaps and future research priorities. We found that RST are currently used across many different research fields to assess changes in plant health and production (agricultural production) and to monitor and evaluate changes in biodiversity across multiple landscape types (ecology and conservation). In crop pollination research, the use of RST are limited and largely restricted to quantifying remnant habitat use by pollinators by ascertaining the proportion of, and/ or isolation from, a given land use type or local variable. Synchronization between research fields is essential to better understand the spatial and temporal variability in pollinator dependent crop production. RST enable these applications to be scaled across much larger areas than is possible with field-based methods and will facilitate large scale ecological changes to be detected and monitored. We advocate greater use of RST to better understand interactions between pollination, plant health and yield spatial variation in pollinator 
34 dependent crops. This more holistic approach is necessary for decision-makers to improve

35 strategies toward managing multiple land use types and ecosystem services.

\section{Introduction}

37 Crop pollination research straddles multiple disciplines and scales as it concerns the efficiency and

transport of pollen by wild and managed taxa across modified and natural systems. In agricultural systems, pollination services provided by insects are important to $75 \%$ of agricultural crop production, which accounts for about $35 \%$ of global food supply (Klein et al., 2007). Studies that encompass scales relevant to both pollination ecology (plant/tree, landscape) and crop production (field, sub-field) are challenging to conduct using traditional field-based methods. However, if we are to better understand the complex interactions that occur in crops between pollination and production, the development or incorporation of methods and technologies that can facilitate the integration of multiple scales is required.

Remote sensing is defined as the measurement of an object or phenomenon without making physical contact, through the detection of reflected or emitted electromagnetic energy (Mulla, 2013). For the assessment of vegetation, remote sensing provides a non-destructive measure of plant status via a range of sensor types (active or passive), resolutions (spatial, temporal, spectral and radiometric) and platforms (satellite, airborne or ground based) (Mulla, 2013). There are multiple benefits for utilising this technology within pollination research, including providing significant opportunities to connect pollination research with other areas already utilising this technology (Figure 1). For example, in ecology and conservation, remotely sensed data has been used in biodiversity monitoring and assessment across most habitat types (Kerr \& Ostrovsky, 2003; Pettorelli et al., 2005; Pettorelli et al., 2011; Pettorelli et al., 2014; de Araujo Barbosa, 
56 Atkinson, \& Dearing, 2015; Galbraith et al., 2015). Applications have included mapping habitat

57 availability, habitat suitability and distributions of threatened species (Osborne, Alonso, \& Bryant,

58 2001; Luoto, Kuussaari, \& Toivonen, 2002; Adhikari, Barik, \& Upadhaya, 2012) and pest or

59 invasive species (Andrew \& Ustin, 2009; Diao \& Wang, 2014), vegetation structure and

60 monitoring (Seavy, Viers, \& Wood, 2009) and biomass estimations (Dong et al., 2003). This

61 information is then used to inform conservation and biodiversity management decisions (Gillespie

62 et al. 2008). RST enable these applications to be scaled across much larger areas than is possible

63 with field-based methods (Kerr \& Ostrovsky, 2003). In addition, RST offer a standardized, regular

64 source of data allowing large scale ecological changes to be detected and monitored (Pettorelli et

65 al., 2014). For example, at a global ecological scale, remote sensing is assisting with the monitoring

66 and mapping anthropogenic impacts including habitat loss, due to deforestation and land

67 conversion, as well as those induced by climate change such as species distribution changes and

68 growing season length (Kerr \& Ostrovsky, 2003; Pettorelli et al., 2005).

Remote sensing technologies are also used widely in the agricultural sciences to better understand the spatial and temporal variation in crop vigour and productivity and for the monitoring of abiotic and biotic constraints across a range of scales (Mahlein et al., 2012; Mulla, 2013). In crop production, specific examples include yield forecasting and mapping (GopalaPillai \& Tian, 1999; Baez-Gonzalez et al., 2005; Zaman, Schumann, \& Hostler, 2006; Robson, Rahman, \& Muir, 2017), water and nutrient monitoring and variable rate applications (Zaman, Schumann, \& Miller, 2005; Goffart, Olivier, \& Frankinet, 2008; Hedley \& Yule, 2009; Tremblay et al., 2009; Barker \&

77 Sawyer, 2010), growth monitoring (Gao et al., 2017), disease detection (Zhang et al., 2003;

Mahlein et al., 2012; Salgadoe et al., 2018), orchard flower assessments (Horton et al., 2017; 
Wang, Underwood, \& Walsh, 2018) and weed control (Lamb \& Brown, 2001). Many crops can now be managed or monitored at multiple scales from individual plants and within field management zones (Zhang, Wang, \& Wang, 2002; Mulla, 2013; Aggelopooulou et al., 2013) through to regional, national and even global scales (Wu et al., 2014). For example, in apple crops the radiometric productive foliar index was developed from the relationship between tree canopy area, normalized difference vegetation index (NDVI) and fruit per tree to better predict crop loads (production per tree $(\mathrm{kg})$ ), fruit quality measures (fruit weight (g) and soluble solids (Brix)) (Best Salazar, Bastías, \& Leon, 2008), while at broader regional, national and global scales, crop montioring systems utilise a combination of remote sensing data and field data to guage estimates of crop production, yield and condition (Wu et al., 2014).

Crop pollination research has utilised remote sensing technologies to understand landscape and regional scale habitat use by pollinating insects. Pollinators are highly mobile, and some can travel many kilometres for the purpose of foraging and nesting (Wikelski et al., 2010). They are impacted by variations in habitat proximity and availability (Carvalheiro et al., 2011), with many having nesting and foraging needs directly dependent on specific habitats and some requiring diverse floral resources for year-round foraging needs (Winfree, Bartomeus, \& Cariveau, 2011; Kennedy et al., 2013). In a crop environment, variations to insect pollinator movement across different scales can result in downstream variations to pollination and the quantity and quality of crop yields. For example, at local field scales, pollinators can constantly move into and out of flowering crops (Mesa et al., 2013), with temporal distributions being significantly influenced by the surrounding landscape (Holzschuh et al., 2011). Although flies and bees have been shown to move distances of several hundred metres between the surrounding environment and flowering crops (Rader et al., 2011), studies examining pollinator abundance and efficiency are often limited beyond very local 
102 scales (individual plants or groups of neighboring plants within a field). While these studies are

103 important for understanding downstream production of fruit and seed set at the plant or within

104 plant scale, they fail to fully elucidate the mechanisms underlying field level variations in crop 105 yield (Angadi et al., 2003). In addition, realised crop yields can also be affected by important 106 interacting and confounding factors that vary within and between fields, including plant 107 reproductive strategies, nutrient and water availability, pest pressure, soil health and profile, light 108 availability, crop density and plant health (Esparza et al., 2001; Bos et al., 2007; Lundin et al., 109 2013; Motzke et al., 2015; Klein et al., 2015). These multiple and potentially interacting biotic and 110 abiotic factors may also influence pollination success. Remote sensing technologies can already 111 detect the signatures of several of these variables (Apostol et al., 2003) and therefore, offers much 112 needed scope to be able to explore these interactions at a range of scales. Such studies are a 113 necessary building block in the development of better tailored management practices that optimize 114 pollination and hence yield outcomes for crop growers.

115 In this study, we conducted a systematic literature review to evaluate the utility of remote sensing 116 technology in crop pollination research. We identify the current suite of remote sensing tools being 117 used, their mode of integration into pollination research, and the unaddressed future research 118 questions that could be answered using RST in crop pollination research.

\section{Materials and Methods}

\section{Literature Search}

121 A literature search using Scopus and Google Scholar identified the types of remote sensing tools

122 utilised in crop pollination research on 14 July 2016 and 11 January 2018. The search terms 123 included 'pollination' or pollinator* and 'landscape*' or 'spatial' or 'land cover' or 'aerial image*' 
124 or 'remote sensing' or 'satellite' or 'tracking' and 'crop' or 'tree' and 'yield' or 'fruit set' or 'fruit 125 quality' and 'wild bee' or 'fly' or 'diptera' or 'beetle' or 'native bee' or 'bee' or 'syrphid' or 'hover 126 fly' or 'hymenoptera' or 'ant' or 'coleoptera'. The reference and citation lists of each article 127 identified were also searched, using these same search terms to source additional research papers. 128 Papers were excluded from the database if crop types were not specified. For example, if papers 129 referred to production systems in a general way such as 'agroecosystem' or 'agricultural matrix' 130 with no further detail about specific crop type, they were excluded.

131 For each publication we recorded: author/s, journal, year of publication, location of study, crop 132 type, type of remote sensing technologies used (Figure 1), the spatial factors reported (e.g. 133 proportion or distance to a given land use). We classified each study according to one of three 134 biome types, tropical, subtropical or temperate. The types of insect pollinators investigated in each 135 paper were recorded and categorised into three main groups: managed honey bees (Apis mellifera), 136 wild bees (unmanaged Apis bees and other non-Apis bees, including solitary and social species) 137 and other wild insects (beetles, non-syrphid and syrphid flies, butterflies and moths). Insect 138 pollinator response variables reported in studies were classified into four categories: species 139 richness (number of different species), species abundance (number of individuals of a single 140 species), functional complementarity (how species complement each other in terms of time of 141 visitation, purpose of visit etc.) and community composition (measure of species richness and 142 abundance combined). Finally, we recorded the metric used to measure pollination success. These 143 were categorised into five groups: yield, fruit set, seed set, fruit quality or other (pollen tube or 144 grain counts). 
145 Results

146 Remote sensing technologies used

147 We identified a total of 68 journal articles (SI Table 1) that utilised some form of RST to facilitate

148 crop pollination research across 33 different crops (Figures S1-4, including general features of data

149 set). The main forms of RST reported in the literature included sourcing aerial (18\%) or satellite

150 imagery $(12 \%)$, using government produced land cover maps $(22 \%)$ or GPS units $(12 \%)$. One

151 study was able to access spatially assessed yield data collected via a harvester mounted yield

152 sensor, while another $12 \%$ used base maps provided by software programs such as Google Earth ${ }^{\mathrm{TM}}$

153 and ArcGIS ${ }^{\circledR}$ rather than sourcing other imagery. Two papers in the database reported using the

154 outputs from RST but no mention was made of how they obtained this information. The remaining

$15521 \%$ of papers used combinations of these technologies. The most common use for the imagery

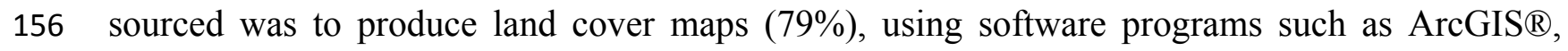

157 ENVI ${ }^{\circledR}$ or Google Earth ${ }^{\mathrm{TM}}$.

158 Methods for incorporating RST

159 Two methods for incorporating RST into crop pollination were apparent in the literature, broadly

160 defined as proportion and isolation (Figure 2). Proportion involved creating a set perimeter (i.e.

161 radius of $500 \mathrm{~m}, 1 \mathrm{~km}$ or $2 \mathrm{~km}$ ) around the focal crop site and then using the proportion of one or

162 more land-use types within that perimeter to explain variations in insect spatial patterns,

163 pollination services or pollination success. Landscape types commonly used included non-

$164 \mathrm{crop} / \mathrm{semi}$-natural habitat and agricultural/crop. This was the most commonly adopted method

165 across studies (51\%).

166 Isolation was used by $12 \%$ of studies. This method measured isolation of a specific crop site or 167 point within a crop site, from landscape or local scale variables, such as natural vegetation patches, 
168 natural vegetation strips, natural vegetation margins or honey bee hives. Thirty-one percent of

169 studies used both proportion and isolation when investigating pollination-related spatial patterns

170 in crops. The remaining $6 \%$ of studies assessed spatial variability in various ways including

171 combining decoded honey bee (Apis mellifera) waggle dances with aerial photographs of the study

172 area to generate foraging distribution maps (Balfour \& Ratnieks, 2016), combining spatial

173 positions within a crop (edge vs centre) with isolation and/or proportion (Gibbs et al., 2016) or

174 assessing field-level yield variability with distance from hives (Cunningham \& Le Feuvre, 2013).

\section{Pollination related response variables}

177 Most crop pollinator studies investigated the extent to which remnant or non-crop vegetation was associated with species richness and species abundance (49\%), species abundance alone (21\%) or

179 species richness, species abundance and community composition combined (16\%). The remaining $14 \%$ of studies used other various combinations of these variables with some also including functional complementarity and one paper used a measurement of honey bee hives/ha as their response variable.

Only one study directly used RST (harvester-mounted equipment that linked harvested crop to the GPS location within the field) to gain a measure of field level yield variability (Cunningham \& Le Feuvre, 2013). While many other studies (53\%) considered a measure of crop production (yield, fruit set, seed set or fruit quality) in their experiments these were most often measures taken from an individual plant or group of plants rather than whole fields, and most (82\%) were related to the same spatial gradients used for pollinator assessment. 
191 In the existing crop pollination literature, the primary application of remote sensing technology

production systems. This was reported through two main activities 1) using landscape assessments

to measure the proportion of land cover types (predominately non-crop, remnant vegetation) surrounding a crop system; and 2) using landscape assessments to determine the isolation of a crop system from non-crop vegetation. These measures were then used as explanatory factors for pollinator related measures (species abundance and/or richness), with a smaller proportion of studies also investigating production measures (yield, fruit or seed set or quality) using these same spatial explanatory factors. Pollination studies utilising RST in this way have provided invaluable information regarding the influence of landscape and regional scale environmental factors on pollinator abundance and distribution. However, given the use of remote sensing technologies in related research areas such as crop production and ecological disciplines, there is a great deal of potential for its further integration into the field of crop pollination.

Despite the influence of landscape scale vegetation factors on pollinator community composition and foraging behavior, relatively little is known about the features within the vegetation prompting these responses. For example, they may be providing alternative floral resources for adult insects, food sources for the development of larval stages or nesting sites. The current methods adopted within crop pollination research do little to address these questions, as the majority of research uses a coarse level of remotely-derived land cover information (Hofmann et al., 2017) with high levels of variation in landscape classifications between studies. In our review, over 30 different categories for broad landscape types were reported. To standardize multi-site, crop, year and study comparisons (Ne'eman et al., 2010), more consistent descriptions of the vegetation at landscape 
213 and regional levels are needed to better understand the features within the vegetation pollinators

214 are responding to. A range of high resolution RST are already being utilised in other research

215 disciplines to extract vegetation data at these more precise resolutions. For example, aerial LIDAR

216 and multispectral data were combined to distinguish between seven different vegetation structures

217 which ranged from grasslands to tree stands of varying height and composition (defined as seven

218 fuel type categories in the study) in Mediterranean forests (García et al., 2011) and very high spatial

219 resolution data (WorldView-2 satellite) has been used to identify and distinguish between different

220 tree species in a forest environment (Immitzer, Atzberger, \& Koukal, 2012). Integrating this type

221 of technology into current crop pollination research would provide more detailed information

222 about important environmental variables that may be comparable between and within crops, years

223 and regions such as vegetation structure, plant diversity and identity, alternative food resources

224 and nesting habitat. This information would also further inform attempts to model and map

225 pollinator species distributions and pollination services (Lonsdorf et al., 2009; Polce et al., 2013).

226 Measuring the impact of the spatial and temporal fluctuations in insect pollinator communities in

227 terms of pollination service provisioning and crop production is still limited for crop pollination

228 research. For example, pollination response variables (visitation, pollen deposition, fruit set and

229 yield) are typically examined at a single plant or row level within a crop field, and while the

230 logistics of conducting these localised experiments often prevent them being conducted at larger

231 scales, they provide little information about the impact of pollination service provisioning at whole

232 field scales. On the other hand, some studies utilise sub-sampling to gain measures that are

233 representative of the whole field (Goodwin et al., 2011), while this may provide more indicative

234 field level results it still holds a degree of coarseness. RST can greatly overcome this coarseness,

235 by providing a far more directed method for deciding where to sample within a field, ultimately 
236 saving time and effort. Cunningham and Le Feuvre (2013) provide one example of how RST can

237 be incorporated to provide field level assessments of pollination service provisioning. Pollination

238 surveys and flower assessments across a whole crop field, designed as a gradient of distance from

239 managed honey bee hives, were used in conjunction with field level yield maps, derived using

240 harvester mounted RST equipment, to determine the effect of managed honey bee density and

241 pollination on yield.

242 Pollination studies also typically treat crop fields as a single uniform factor in all respects aside

243 from their isolation from or proportion of surrounding landscape and local variables, despite crop

244 production research showing that yield variability can differ both between and within fields

245 (Robson, Rahman, \& Muir, 2017). In comparison, precision agricultural studies recognise field

246 level variability of factors such as nutrients, water stress, soil characteristics and plant health,

247 which impact on final yield measures (Zaman, Schumann, \& Miller, 2005; Hedley \& Yule, 2009;

248 Barker \& Sawyer, 2010). Pollination services are typically investigated in isolation from these

249 important abiotic factors that influence yield outcomes. However, a small number of studies have

250 investigated interactions in crop species between pollination, water and nutrients in almond (Klein

251 et al., 2015), pollination, pesticide and fertilizer in cucumber (Motzke et al., 2015) and pollination,

252 light intensity, nitrogen and water stress in cacao (Groeneveld et al., 2010). In all three studies,

253 pollination was the most important driver of yield variability, with fruit set being lowest when

254 insect pollinators were excluded. However, interactions between pollination and reduced water in

255 almond, pollination and weed control in cucumber and pollination intensity and light intensity in

256 cacao indicate that these need to be more readily incorporated into crop pollination studies

257 (Groeneveld et al., 2010; Klein et al., 2015; Motzke et al., 2015). RST provides the opportunity to 258 use fine-scale measurements of abiotic and environmental factors, such as nutrient or water 
259 availability, to unravel their possible interactions with pollination success and assess the field-level

260 heterogeneity of these interactions (Kerr \& Ostrovsky, 2003; Pettorelli et al., 2005; de Araujo

261 Barbosa, Atkinson, \& Dearing, 2015; Galbraith, Vierling, \& Bosque-Pérez, 2015). For example,

262 combining factors important to insect pollinators, such as surrounding vegetation, with field

263 surveys specifically targeted to capture the varying levels of tree or plant stress (water, nutrients,

264 light interception) across a whole field, provide significant opportunities to evaluate these

265 interactions and assess their impact on production measures. RST also offers significant

266 opportunities to evaluate whether fine-scale ecological processes that influence pollination success

267 (e.g. pollinator complementarity) are operating on a much broader scales in a landscape.

268 To achieve this, several challenges still need to be addressed to enable greater integration of

269 remotely-derived data into crop pollination ecology research. First, access to high resolution

270 remotely sensed data can be costly (Rose et al., 2015; Turner et al., 2015). Many of the studies

271 identified in this review utilised freely available land use maps or images provided by Government

272 departments or publicly available through sources such as Google Earth ${ }^{\mathrm{TM}}$. While these have been

273 well utilised for determining isolation and proportion measures across these studies, they provide

274 a relatively coarse spatial, spectral and temporal resolution of remotely-derived information

275 compared to what is now commercially available and required in many disciplines (Hofmann et

276 al., 2017). Second, expert knowledge is required to understand how RST may be best utilised and

277 applied in crop pollination research. Factors to be considered in this process include understanding

278 the type of RST needed and what information the associated data can provide. For example,

279 general patterns of pollinator response to satellite-derived land cover and vegetation information

280 may be further refined through the addition of local structural information of vegetation, which

281 can be increasingly accurately estimated using LIDAR (Lefsky et al., 2002; Andrew, Wulder, \& 
282 Nelson, 2014). In addition, the information provided by RST needs to be validated through some

283 form of ground-truthing (such as ground-based teams of researchers or sensors) as well as being

284 inspected for possible distortions (atmospheric effects, cloud cover, mechanical issues) (Turner et

285 al., 2003; Andrew et al., 2014). An increased collaborative effort at all stages of the experimental

286 process, between remote sensing experts, crop production and pollination researchers as well as

287 growers and industry stakeholders would enable greater transfer of knowledge among disciplines

288 and facilitate applied outcomes for management.

289 Understanding how far insect crop pollinators move within and among crops and other habitats is 290 another important future research direction. While several technologies exist to track animal 291 movement at various spatial scales, including radio telemetry, satellite tracking, harmonic radar 292 and radio frequency identification (Law \& Lean, 1999; Bonadonna, Lea, \& Guinet, 2000; 293 Bontadina, Schofield, \& Naef-Daenzer, 2002; Godley et al., 2008; Cagnacci et al., 2010; Thomas, 294 Baker, \& Fellowes, 2014), the small size of insects currently limit the use of these types of 295 technologies (Kissling et al., 2014). Micro-transmitters have successfully been deployed to track 296 several larger insect species, such as bumble bees, orchid bees and carpenter bees (Osborne et al., 297 1999; Pasquet et al., 2008; Wikelski et al., 2010; Hagen, Wikelski, \& Kissling, 2011) however 298 technologies for small to medium pollinators, such as wild bees and hoverflies, are limited. As 299 these technologies become more advanced they may soon become a viable option for more detailed 300 investigations of pollinating insect movement distances within crop pollination research.

As our dependency on pollination services increase, predominately through greater cultivation of 304 pollinator-dependent crops (Aizen et al., 2008; Potts et al., 2010), understanding the spatial and 
temporal stability of pollination service provisioning is becoming increasingly relevant.

306 Relationships between pollinator community structure (abundance, richness and evenness) and

307 broad landscape factors as well as pollination services and yield at a single tree or plant level are

308 well established. What is missing is data and an approach that elucidates on the role of pollination

309 at the field and broader scales. This will facilitate our understanding of interactions between

310 pollinators, pollination services and other important environmental, abiotic and pre- and post-

311 pollination factors, such as plant health, water and nutrients, which affect final harvest measures.

312 The further integration of remote sensing technologies may be one approach to investigating these

313 important interactions and an increased collaborative effort between agricultural and pollination

314 ecology researchers, remote sensing experts as well as key industry stakeholders such as growers

315 will help ensure outcomes that are more applicable for managing multiple land use types and 316 ecosystem services.

317

318

319

320

321

322

323

324

325

326

327

328

329

\section{References}

Adhikari D, Barik S, \& Upadhaya K. 2012. Habitat distribution modelling for reintroduction of Ilex khasiana Purk., a critically endangered tree species of northeastern India. Ecological Engineering 40:37-43 DOI: 10.1016/j.ecoleng.2011.12.004.

Aggelopooulou K, Castrignanò A, Gemtos T, De Benedetto D. 2013. Delineation of management zones in an apple orchard in Greece using a multivariate approach. Computers and electronics in agriculture 90:119-130 DOI: 10.1016/j.compag.2012.09.009.

Aizen MA, Garibaldi LA, Cunningham SA, Klein AM. 2008. Long-term global trends in crop yield and production reveal no current pollination shortage but increasing pollinator dependency. Current Biology 18(20):1572-1575 DOI: 10.1016/j.cub.2008.08.066. 
330

331

332

333

334

335

336

337

338

339

340

341

342

343

344

345

346

347

348

349

350

351

352

353

354

355

356

357

358

359

360

361

362
Andrew ME, Ustin SL. 2009. Habitat suitability modelling of an invasive plant with advanced remote sensing data. Diversity and Distributions 15(4):627-640 DOI: 10.1111/j.14724642.2009.00568.x.

Andrew ME, Wulder MA, Nelson TA. 2014. Potential contributions of remote sensing to ecosystem service assessments. Progress in Physical Geography 38(3):328-353 DOI: $10.1177 / 0309133314528942$.

Angadi S, Cutforth H, McConkey B, Gan Y. 2003. Yield adjustment by canola grown at different plant populations under semiarid conditions. Crop Science 43(4):1358-1366

Apostol S, Viau AA, Tremblay N, Briantais JM, Prasher S, Parent LE, Moya I. 2003. Laserinduced fluorescence signatures as a tool for remote monitoring of water and nitrogen stresses in plants. Canadian journal of remote sensing 29(1):57-65 DOI: $10.5589 / \mathrm{m02}-$ 076.

Baez-Gonzalez AD, Kiniry JR, Maas SJ, Tiscareno ML, Macias C, Mendoza JL, Richardson CW, Salinas G, Manjarrez JR. 2005. Large-area maize yield forecasting using leaf area index based yield model. Agronomy Journal 97(2):418-425.

Balfour, NJ, Ratnieks FL. 2016. Using the waggle dance to determine the spatial ecology of honey bees during commercial crop pollination. Agricultural and Forest Entomology 19(2):210216 DOI: $10.1111 /$ afe.12204.

Barker DW, Sawyer JE. 2010. Using active canopy sensors to quantify corn nitrogen stress and nitrogen application rate. Agronomy Journal 102(3):964-971 DOI: 10.2134/agronj2010.0004.

Best S, Salazar F, Bastías R, Leon L. 2008. Crop load estimation model to optimize yield-quality ratio in apple orchards, Malus Domestica Borkh, Var. Royal Gala. Journal of Information Technology in Agriculture 3(1):11-18.

Bonadonna F, Lea MA, Guinet C. 2000. Foraging routes of Antarctic fur seals (Arctocephalus gazella) investigated by the concurrent use of satellite tracking and time-depth recorders. Polar Biology 23(3):149-159 DOI: 10.1007/s003000050021.

Bontadina F, Schofield H, Naef-Daenzer B. 2002. Radio-tracking reveals that lesser horseshoe bats (Rhinolophus hipposideros) forage in woodland. Journal of Zoology 258(3):281-290 DOI: $10.1017 / \mathrm{S} 0952836902001401$. 
Bos MM, Veddeler D, Bogdanski AK, Klein AM, Tscharntke T, Steffan-Dewenter I, Tylianakis JM. 2007. Caveats to quantifying ecosystem services: fruit abortion blurs benefits from crop pollination. Ecological Applications 17(6):1841-1849 DOI: 10.1890/06-1763.1.

Bradbury RB, Hill RA, Mason DC, Hinsley SA, Wilson JD, Balzter H, Anderson GQA, Whittingham MJ, Davenport IJ, Bellamy PE. 2005. Modelling relationships between birds and vegetation structure using airborne LiDAR data: a review with case studies from agricultural and woodland environments. Ibis 147(3):443-452 DOI: 10.1111/j.1474919x.2005.00438.x.

Cagnacci F, Boitani L, Powell RA, Boyce MS. 2010. Animal ecology meets GPS-based radiotelemetry: a perfect storm of opportunities and challenges. Proceedings of the Royal Society of London B: Biological Sciences 365(1550):2157-2162 DOI: 10.1098/rstb.2010.0107.

Cao Q, Miao Y, Shen J, Yu W, Yuan F, Cheng S, Huang S, Wang H, Yang W, Liu F. 2016. Improving in-season estimation of rice yield potential and responsiveness to topdressing nitrogen application with Crop Circle active crop canopy sensor. Precision Agriculture 17(2):136-154 DOI 10.1007/s11119-015-9412-y.

Carvalheiro LG, Veldtman R, Shenkute AG, Tesfay GB, Pirk CWW, Donaldson JS, Nicolson SW. 2011. Natural and within-farmland biodiversity enhances crop productivity. Ecology Letters 14(3):251-259 DOI: 10.1111/j.1461-0248.2010.01579.x.

Cunningham SA, Le Feuvre D. 2013. Significant yield benefits from honeybee pollination of faba bean (Vicia faba) assessed at field scale. Field crops research 149:269-275 DOI: 10.1016/j.fcr.2013.05.019.

de Araujo Barbosa CC, Atkinson PM, Dearing JA. 2015. Remote sensing of ecosystem services: A systematic review. Ecological Indicators 52:430-443 DOI: 10.1016/j.ecolind.2015.01.007.

Diao C, Wang L. 2014. Development of an invasive species distribution model with fine-resolution remote sensing. International Journal of Applied Earth Observation and Geoinformation 30:65-75 DOI: 10.1016/j.jag.2014.01.015.

Dong J, Kaufmann RK, Myneni RB, Tucker CJ, Kauppi PE, Liski J, Buermann W, Alexeyev V, Hughes MK. 2003. Remote sensing estimates of boreal and temperate forest woody biomass: carbon pools, sources, and sinks. Remote Sensing of Environment 84(3):393-410 DOI: 10.1016/S0034-4257(02)00130-X. 
398

399

400

401

402

403

404

405

406

407

408

409

410

411

412

413

414

415

416

417

418

419

420

421

422

423

424

425

426
Esparza G, DeJong T, Weinbaum S, Klein I. 2001. Effects of irrigation deprivation during the harvest period on yield determinants in mature almond trees. Tree Physiology 21(14):10731079 DOI: 10.1093/treephys/21.14.1073.

Galbraith SM, Vierling L, Bosque-Pérez N. 2015. Remote Sensing and Ecosystem Services: Current Status and Future Opportunities for the Study of Bees and Pollination-Related Services. Current Forestry Reports 1(4):261-274 DOI: 10.1007/s40725-015-0024-6.

Gao F, Anderson MC, Zhang X, Yang Z, Alfieri JG, Kustas WP, Mueller R, Johnson DM, Prueger JH. 2017. Toward mapping crop progress at field scales through fusion of Landsat and MODIS imagery. Remote Sensing of Environment 188:9-25 DOI: 10.1016/j.rse.2016.11.004.

García M, Riaño D, Chuvieco E, Salas J, Danson FM. 2011. Multispectral and LiDAR data fusion for fuel type mapping using Support Vector Machine and decision rules. Remote Sensing of Environment 115(6):1369-1379 DOI: 10.1016/j.rse.2011.01.017.

Garibaldi LA, Steffan-Dewenter I, Winfree R, Aizen MA, Bommarco R, Cunningham SA, Kremen C, Carvalheiro LG, Harder LD, Afik O. 2013. Wild pollinators enhance fruit set of crops regardless of honey bee abundance. Science 339(6127):1608-1611 DOI: $10.1126 /$ science. 1230200 .

Gibbs J, Elle E, Bobiwash K, Haapalainen T, Isaacs R. 2016. Contrasting pollinators and pollination in native and non-native regions of highbush blueberry production. PloS one 11(7):e0158937 DOI: 10.1371/journal.pone.0158937.

Gillespie TW, Foody GM, Rocchini D, Giorgi AP, Saatchi S. 2008. Measuring and modelling biodiversity from space. Progress in Physical Geography 32(2):203-221 DOI: 10.1177/0309133308093606.

Godley BJ, Blumenthal J, Broderick A, Coyne M, Godfrey M, Hawkes L, Witt M. 2008. Satellite tracking of sea turtles: where have we been and where do we go next? Endangered Species Research 4(1-2):3-22 DOI: 10.3354/esr00060.

Goffart J, Olivier M, Frankinet M. 2008. Potato crop nitrogen status assessment to improve N fertilization management and efficiency: Past-present-future. Potato Research 51(34):355-383 DOI: 10.1007/s11540-008-9118-x.

Goodwin R, Cox H, Taylor M, Evans L, McBrydie H. 2011. Number of honey bee visits required to fully pollinate white clover (Trifolium repens) seed crops in Canterbury, New Zealand. 
429

430

431

432

433

434

435

436

437

438

439

440

441

442

443

444

445

446

447

448

449

450

451

452

453

454

455

456

New Zealand Journal of Crop and Horticultural Science 39(1):7-19 DOI: 10.1080/01140671.2010.520164.

GopalaPillai S, Tian L. 1999. In-field variability detection and spatial yield modeling for corn using digital aerial imaging. Transactions of the ASAE 42(6):1911 DOI: $10.13031 / 2013.13356$.

Groeneveld JH, Tscharntke T, Moser G, Clough Y. 2010. Experimental evidence for stronger cacao yield limitation by pollination than by plant resources. Perspectives in Plant Ecology, Evolution and Systematics 12(3):183-191 DOI: 10.1016/j.ppees.2010.02.005.

Hagen M, Wikelski M, Kissling WD. 2011. Space use of bumblebees (Bombus spp.) revealed by radio-tracking. PloS one 6(5):e19997 DOI: 10.1371/journal.pone.0019997.

Hedley C, Yule I. 2009. A method for spatial prediction of daily soil water status for precise irrigation scheduling. Agricultural Water Management 96(12):1737-1745 DOI: 10.1016/j.agwat.2009.07.009.

Hofmann S, Everaars J, Schweiger O, Frenzel M, Bannehr L, Cord AF. 2017. Modelling patterns of pollinator species richness and diversity using satellite image texture. PloS one 12(10):e0185591 DOI: 10.1371/journal.pone.0185591.

Holzschuh A, Dormann CF, Tscharntke T, Steffan-Dewenter I. 2011. Expansion of massflowering crops leads to transient pollinator dilution and reduced wild plant pollination. Proceedings of the Royal Society of London B: Biological Sciences 278(1723):3444-3451 DOI: $10.1098 / \mathrm{rspb} .2011 .0268$

Horton R, Cano E, Bulanon D, Fallahi E. 2017. Peach Flower Monitoring Using Aerial Multispectral Imaging. Journal of Imaging 3(1):2 DOI: 10.3390/jimaging3010002.

Immitzer M, Atzberger C, Koukal T. 2012. Tree species classification with random forest using very high spatial resolution 8-band WorldView-2 satellite data. Remote Sensing 4(9):26612693 DOI: $10.3390 /$ rs4092661.

Joyce KE, Belliss SE, Samsonov SV, McNeill SJ, Glassey PJ. 2009. A review of the status of satellite remote sensing and image processing techniques for mapping natural hazards and disasters. Progress in Physical Geography 33(2):183-207 DOI: $10.1177 / 0309133309339563$. 
457

458

459

460

461

462

463

464

465

466

467

468

469

470

471

472

473

474

475

476

477

478

479

480

481

482

483

484

485

Kennedy CM, Lonsdorf E, Neel MC, Williams NM, Ricketts TH, Winfree R, Bommarco R, Brittain C, Burley AL, Cariveau D. 2013. A global quantitative synthesis of local and landscape effects on wild bee pollinators in agroecosystems. Ecology Letters 16(5):584599 DOI: 10.1111/ele.12082.

Kerr JT, Ostrovsky M. 2003. From space to species: ecological applications for remote sensing. Trends in ecology \& evolution 18(6):299-305 DOI: 10.1016/S0169-5347(03)00071-5.

Kissling DW, Pattemore DE, Hagen M. 2014. Challenges and prospects in the telemetry of insects. Biological Reviews 89(3):511-530 DOI: 10.1111/brv.12065.

Klein AM, Vaissiere BE, Cane JH, Steffan-Dewenter I, Cunningham SA, Kremen C, \& Tscharntke T. 2007. Importance of pollinators in changing landscapes for world crops. Proceedings of the Royal Society of London B: Biological Sciences 274(1608):303-313 DOI: 10.1098/rspb.2006.3721.

Klein AM, Hendrix SD, Clough Y, Scofield A, Kremen C. 2015. Interacting effects of pollination, water and nutrients on fruit tree performance. Plant Biology 17(1):201-208 DOI: 10.1111/plb.12180.

Lamb D, Brown RB. 2001. Pa—precision agriculture: Remote-sensing and mapping of weeds in crops. Journal of Agricultural Engineering Research 78(2):117-125 DOI: 10.1006/jaer.2000.0630.

Law BS, Lean M. 1999. Common blossom bats (Syconycteris australis) as pollinators in fragmented Australian tropical rainforest. Biological Conservation 91(2-3):201-212 DOI: 10.1016/S0006-3207(99)00078-6.

Lefsky MA, Cohen WB, Parker GG, Harding DJ. 2002. Lidar remote sensing for ecosystem studies: Lidar, an emerging remote sensing technology that directly measures the threedimensional distribution of plant canopies, can accurately estimate vegetation structural attributes and should be of particular interest to forest, landscape, and global ecologists. AIBS Bulletin 52(1):19-30 DOI: 10.1641/0006-3568(2002)052[0019:LRSFES]2.0.CO;2.

Llorens J, Gil E, Llop J, Escola A. 2011. Ultrasonic and LIDAR sensors for electronic canopy characterization in vineyards: Advances to improve pesticide application methods. Sensors 11(2):2177-2194 DOI: 10.3390/s110202177. 
486

487

488

489

490

491

492

493

494

495

496

497

498

499

500

501

502

503

504

505

506

507

508

509

510

511

512

513

514

515

516

Lonsdorf E, Kremen C, Ricketts T, Winfree R, Williams N, Greenleaf S. 2009. Modelling pollination services across agricultural landscapes. Annals of Botany 103(9):1589-1600 DOI: $10.1093 / \mathrm{aob} / \mathrm{mcp} 069$.

Luoto M, Kuussaari M, Toivonen T. 2002. Modelling butterfly distribution based on remote sensing data. Journal of Biogeography 29(8):1027-1037 DOI: 10.1046/j.13652699.2002.00728.x.

Lundin O, Smith HG, Rundlöf M, Bommarco R. 2013. When ecosystem services interact: crop pollination benefits depend on the level of pest control. Proceedings of the Royal Society of London B: Biological Sciences 280(1753):2012-2243 DOI: 10.1098/rspb.2012.2243.

Mahlein AK, Oerke EC, Steiner U, Dehne HW. 2012. Recent advances in sensing plant diseases for precision crop protection. European Journal of Plant Pathology 133(1):197-209 DOI: 10.1007/s10658-011-9878-z.

Marino S, Alvino A. 2014. Proximal sensing and vegetation indices for site-specific evaluation on an irrigated crop tomato. European Journal of Remote Sensing 47(1):271-283 DOI: $10.5721 /$ EuJRS20144717.

Mesa LA, Howlett BG, Grant JE, Didham RK, Ni X. 2013. Changes in the relative abundance and movement of insect pollinators during the flowering cycle of Brassica rapa crops: implications for gene flow. Journal of Insect Science 13(1):13 DOI: 10.1673/031.013.1301.

Motzke I, Tscharntke T, Wanger TC, Klein AM. 2015. Pollination mitigates cucumber yield gaps more than pesticide and fertilizer use in tropical smallholder gardens. Journal of Applied Ecology 52(1):261-269 DOI: 10.1111/1365-2664.12357.

Mulla DJ. 2013. Twenty five years of remote sensing in precision agriculture: Key advances and remaining knowledge gaps. Biosystems Engineering 114(4):358-371 DOI: 10.1016/j.biosystemseng.2012.08.009.

Ne'eman G, Jürgens A, Newstrom-Lloyd L, Potts SG, Dafni A. 2010. A framework for comparing pollinator performance: effectiveness and efficiency. Biological Reviews 85(3):435-451 DOI: $10.1111 /$ j.1469-185X.2009.00108.x.

Osborne J, Clark S, Morris R, Williams I, Riley J, Smith A, Reynolds DR, Edwards A. 1999. A landscape-scale study of bumble bee foraging range and constancy, using harmonic radar. Journal of Applied Ecology 36(4):519-533 DOI: 10.1046/j.1365-2664.1999.00428.x533. 
517

518

519

520

521

522

523

524

525

526

527

528

529

530

531

532

533

534

535

536

537

538

539

540

541

542

543

544

545

Osborne P, Alonso J, Bryant R. 2001. Modelling landscape-scale habitat use using GIS and remote sensing: a case study with great bustards. Journal of Applied Ecology 38(2):458-471 DOI: 10.1046/j.1365-2664.2001.00604.x.

Pasquet RS, Peltier A, Hufford MB, Oudin E, Saulnier J, Paul L, Knudsen JT, Herren HR, Gepts P. 2008. Long-distance pollen flow assessment through evaluation of pollinator foraging range suggests transgene escape distances. Proceedings of the national Academy of Sciences 105(36):13456-13461 DOI: 10.1073/pnas.0806040105.

Pettorelli N, Laurance WF, O'Brien TG, Wegmann M, Nagendra H, Turner W. 2014. Satellite remote sensing for applied ecologists: opportunities and challenges. Journal of Applied Ecology 51(4):839-848 DOI: 10.1111/1365-2664.12261.

Pettorelli N, Ryan S, Mueller T, Bunnefeld N, Jędrzejewska B, Lima M, Kausrud K. 2011. The Normalized Difference Vegetation Index (NDVI): unforeseen successes in animal ecology. Climate Research 46(1):15-27 DOI: 10.3354/cr00936.

Pettorelli N, Vik JO, Mysterud A, Gaillard JM, Tucker CJ, Stenseth NC. 2005. Using the satellitederived NDVI to assess ecological responses to environmental change. Trends in ecology \& evolution 20(9):503-510 DOI: 10.1016/j.tree.2005.05.011.

Polce C, Termansen M, Aguirre-Gutiérrez J, Boatman ND, Budge GE, Crowe A, Garratt MP, Pietravalle S, Potts SG, Ramirez JA. 2013. Species distribution models for crop pollination: a modelling framework applied to Great Britain. PloS one 8(10):e76308 DOI: 10.1371/journal.pone.0076308.

Potts SG, Biesmeijer JC, Kremen C, Neumann P, Schweiger O, Kunin WE. 2010. Global pollinator declines: trends, impacts and drivers. Trends in ecology \& evolution 25(6):345-353 DOI: 10.1016/j.tree.2010.01.007.

Rader R, Edwards W, Westcott DA, Cunningham SA, Howlett BG. 2011. Pollen transport differs among bees and flies in a human-modified landscape. Diversity and Distributions 17:519529 DOI: 10.1111/j.1472-4642.2011.00757.x.

Robson AJ, Rahman MM, Muir J. 2017. Using Worldview Satellite Imagery to Map Yield in Avocado (Persea americana): A Case Study in Bundaberg, Australia. Remote Sensing 9(12):1223 DOI: 10.3390/rs9121223. 
546

Rose RA, Byler D, Eastman JR, Fleishman E, Geller G, Goetz S, Guild L, Hamilton H, Hansen M, Headley R. 2015. Ten ways remote sensing can contribute to conservation. Conservation Biology 29(2):350-359 DOI: 10.1111/cobi.12397.

Salgadoe ASA, Robson AJ, Lamb DW, Dann EK, Searle C. 2018. Quantifying the Severity of Phytophthora Root Rot Disease in Avocado Trees Using Image Analysis. Remote Sensing 10(2):226 DOI: 10.3390/rs10020226.

Seavy NE, Viers JH, Wood JK. 2009. Riparian bird response to vegetation structure: a multiscale analysis using LiDAR measurements of canopy height. Ecological Applications 19(7):1848-1857 DOI: 10.1890/08-1124.1.

Shahbazi M, Théau J, Ménard P. 2014. Recent applications of unmanned aerial imagery in natural resource management. GIScience \& Remote Sensing 51(4):339-365 DOI: 10.1080/15481603.2014.926650.

Stutchbury BJ, Tarof SA, Done T, Gow E, Kramer PM, Tautin J, Fox JW, Afanasyev V. 2009. Tracking long-distance songbird migration by using geolocators. Science 323(5916):896896 DOI: $10.1126 /$ science. 1166664.

Thomas RL, Baker PJ, Fellowes MD. 2014. Ranging characteristics of the domestic cat (Felis catus) in an urban environment. Urban ecosystems 17(4):911-921 DOI: $10.1007 / \mathrm{s} 11252-$ 014-0360-5.

Tremblay N, Wang Z, Ma BL, Belec C, Vigneault P. 2009. A comparison of crop data measured by two commercial sensors for variable-rate nitrogen application. Precision Agriculture 10(2):145 DOI: 10.1007/s11119-008-9080-2.

Tucker CJ, Townshend JR, Goff TE. 1985. African land-cover classification using satellite data. Science 227(4685):369-375 DOI: 10.1126/science.227.4685.369.

Turner W, Rondinini C, Pettorelli N, Mora B, Leidner AK, Szantoi Z, Buchanan G, Dech S, Dwyer J, Herold M. 2015. Free and open-access satellite data are key to biodiversity conservation. Biological Conservation 182:173-176 DOI: 10.1016/j.biocon.2014.11.048

Turner W, Spector S, Gardiner N, Fladeland M, Sterling E, Steininger M. 2003. Remote sensing for biodiversity science and conservation. Trends in ecology \& evolution 18(6):306-314 DOI: 10.1016/S0169-5347(03)00070-3. 
575

576

577

578

579

580

581

582

583

584

585

586

587

588

589

590

591

592

593

594

595

596

597

598

599

600

601

602

603

604

605
Wang Z, Underwood J, Walsh KB. 2018. Machine vision assessment of mango orchard flowering. Computers and electronics in agriculture 151:501-511 DOI: 10.1016/j.compag.2018.06.040.

Wikelski M, Moxley J, Eaton-Mordas A, Lopez-Uribe MM, Holland R, Moskowitz D, Roubik DW, Kays R. 2010. Large-range movements of neotropical orchid bees observed via radio telemetry. PloS one 5(5):e10738 DOI: 10.1371/journal.pone.0010738.

Winfree R, Bartomeus I, Cariveau DP. 2011. Native pollinators in anthropogenic habitats. Annual Review of Ecology, Evolution, and Systematics 42(1):1-22 DOI: 10.1146/annurev-ecolsys102710-145042.

Wu B, Meng J, Li Q, Yan N, Du X, Zhang M. 2014. Remote sensing-based global crop monitoring: experiences with China's CropWatch system. International Journal of Digital Earth 7(2):113-137 DOI: 10.1080/17538947.2013.821185.

Zaman Q, Schumann A, Hostler H. 2006. Estimation of citrus fruit yield using ultrasonicallysensed tree size. Applied Engineering in Agriculture 22(1):39-44 DOI: $10.13031 / 2013.20186$.

Zaman Q, Schumann A, Miller W. 2005. Variable rate nitrogen application in Florida citrus based on ultrasonically-sensed tree size. Applied Engineering in Agriculture 21(3):331-335 DOI: $10.13031 / 2013.18448$.

Zhang M, Qin Z, Liu X, Ustin SL. 2003. Detection of stress in tomatoes induced by late blight disease in California, USA, using hyperspectral remote sensing. International Journal of Applied Earth Observation and Geoinformation 4(4):295-310 DOI: 10.1016/S03032434(03)00008-4.

Zhang N, Wang M, Wang N. 2002. Precision agriculture-a worldwide overview. Computers and electronics in agriculture 36(2-3):113-132 DOI: 10.1016/S0168-1699(02)00096-0. 
606

607

608

609

610

611

612

613

614

615 


\section{Figure 1 (on next page)}

Examples of remote sensing technologies and their current applications in agricultural and ecological disciplines.

Top image credit: Thegreenj (Wikipedia), First middle image credit: Andrew Robson, Second middle image credit: bdk (Wikimedia Commons), Bottom image credit: CSIRO 
PeerJ
RST platforms (sensor examples)

Manuscript to be reviewed

\begin{tabular}{|c|c|c|}
\hline $\begin{array}{c}\text { PeerJ } \\
\text { RST platforms (sensor examples) }\end{array}$ & $\begin{array}{l}\text { Manuscript to be } \\
\text { Applications }\end{array}$ & Examples \\
\hline $\begin{array}{c}\text { Satellite } \\
\text { (Quickbird, WorldView, SPOT, Landsat, RapidEye) }\end{array}$ & $\begin{array}{l}\text { Land cover mapping, ecosystem } \\
\text { classification and change, natural } \\
\text { disaster assessment, yield mapping }\end{array}$ & $\begin{array}{l}\text { Robson, Rahman, \& Muir, } 2017 \\
\text { Joyce et al., } 2009 \\
\text { Pettorelli et al., } 2005 \\
\text { Tucker, Townshend, \& Goff, } 1985\end{array}$ \\
\hline $\begin{array}{l}\text { Aerial (drones, UAV's, airplanes) } \\
\text { (camera systems e.g. Microsense, Parrot Sequoia) }\end{array}$ & $\begin{array}{l}\text { Land cover mapping, ecosystem } \\
\text { classification and change, natural } \\
\text { disaster assessment, wildlife research, } \\
\text { precision agriculture }\end{array}$ & $\begin{array}{c}\text { Shahbazi, Théau, \& Ménard, } 2014 \\
\text { Horton et al., } 2017\end{array}$ \\
\hline $\begin{array}{l}\text { LIDAR (satellite, aerial or terrestrial) } \\
\text { (2D and 3D laser scanners) }\end{array}$ & $\begin{array}{l}\text { Vegetation (crop and non-crop) mapping } \\
\text { and structure }\end{array}$ & $\begin{array}{l}\text { Bradbury et al., } 2005 \\
\text { Llorens et al., } 2011 \\
\text { Lefsky et al., } 2002\end{array}$ \\
\hline Proximal (tractor or vehicle mounted, handheld devices) & Yield mapping, crop monitoring & $\begin{array}{c}\text { Marino \& Alvino, } 2014 \\
\text { Cunningham \& Le Feuvre, } 2013 \\
\text { Cao et al., } 2016\end{array}$ \\
\hline Tracking technology (harmonic radar, radio telemetry, satellite) & Animal movement and distributions & $\begin{array}{l}\text { Stutchbury et al., 2009; } \\
\text { Osborne et al., 1999; } \\
\text { Pasquet et al., 2008; } \\
\text { Wikelski et al., 2010 }\end{array}$ \\
\hline
\end{tabular}


Figure 2 (on next page)

Examples of proportion and isolation methods.

(A) proportion of non-crop vegetation [green], crop vegetation [orange] and water [blue] within a $500 \mathrm{~m}$ perimeter radius of a focal crop site. (B) distance of non-crop vegetation from a focal crop site. (Images @ 2018 Google) 
A

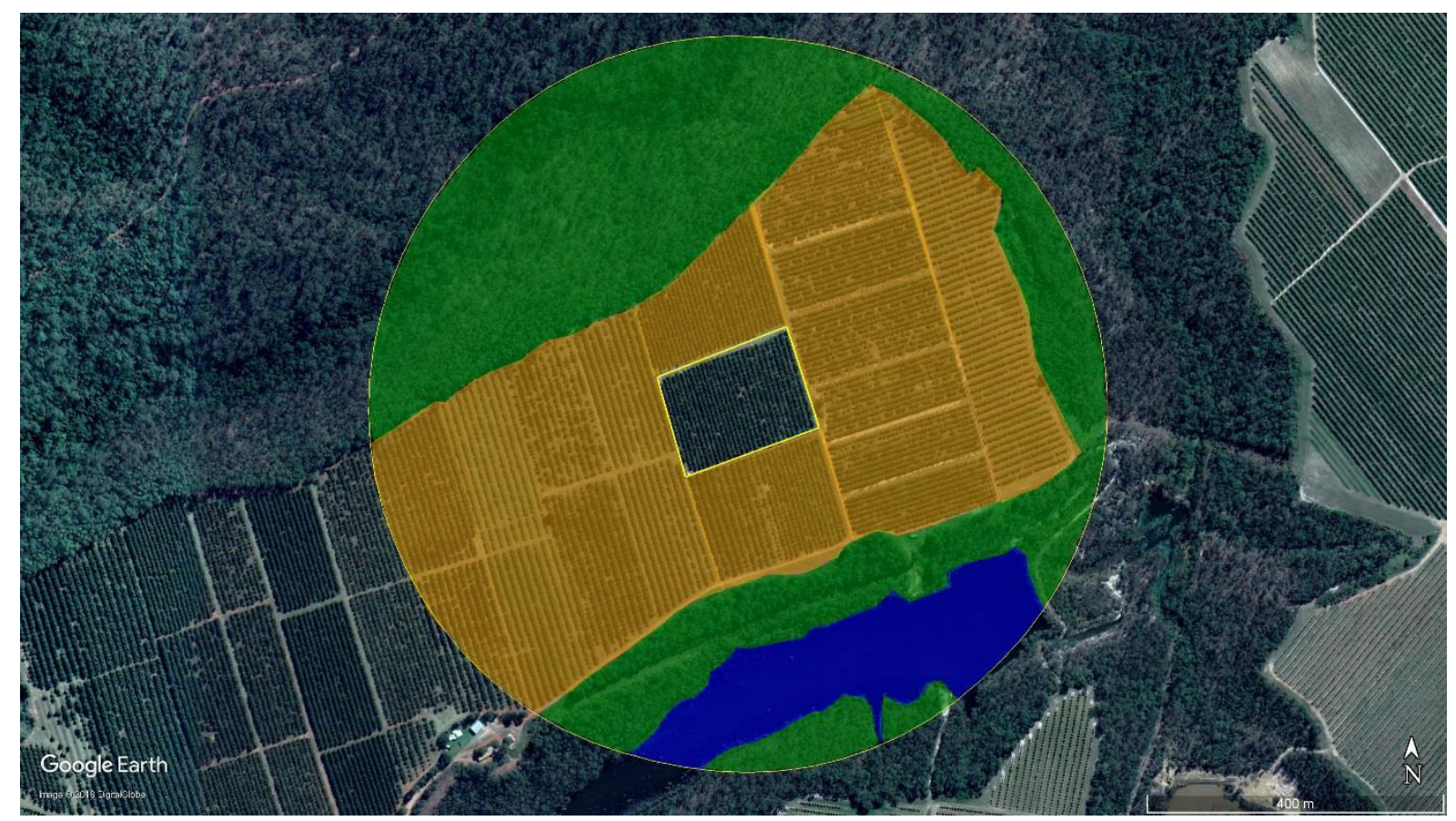

B

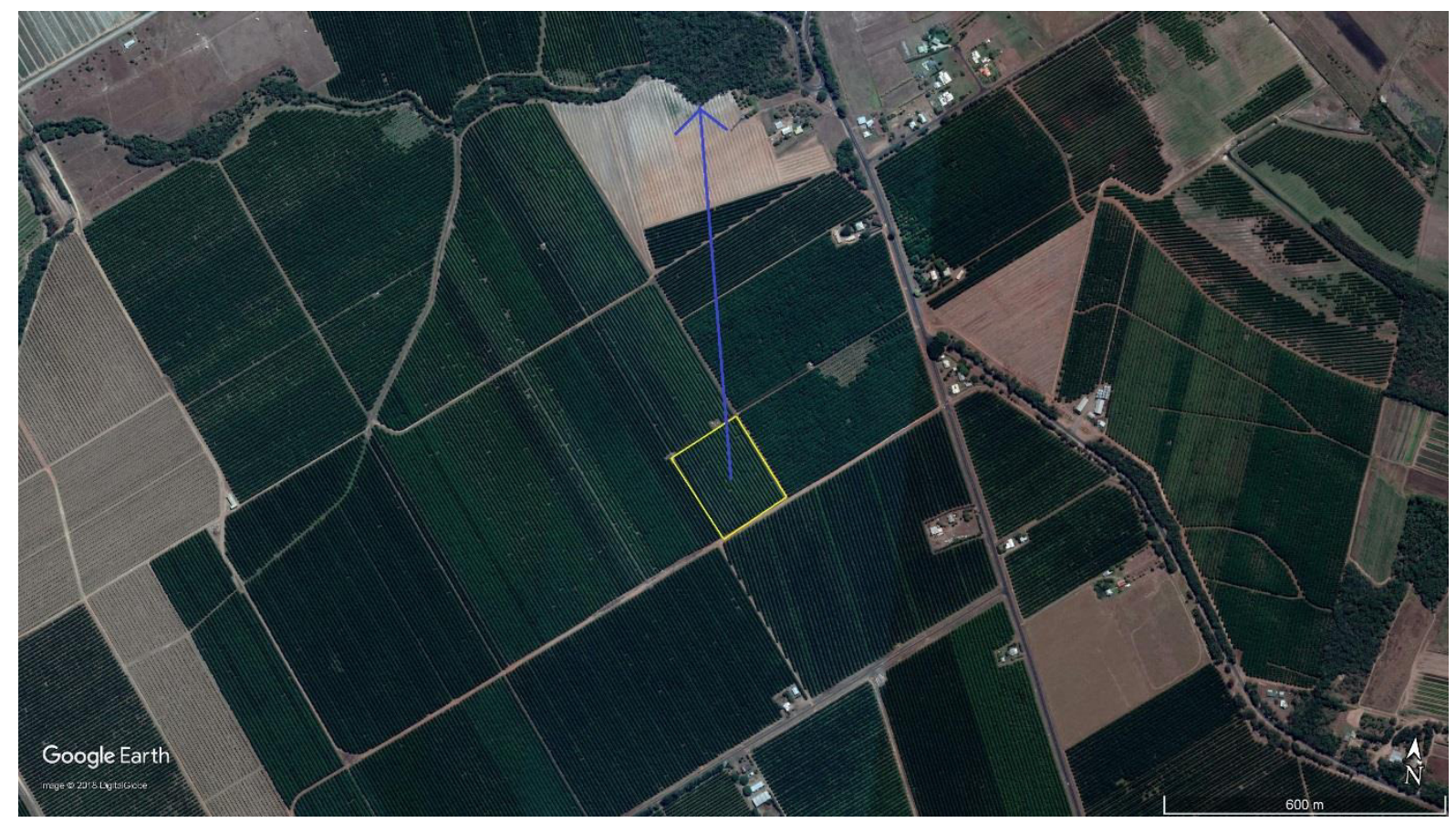

